well-developed typhoid. The accompanying interesting chart, prepared by Dr. Frank L. Morse of the Massachusetts State Board of Health, shows the dates on which the several cases of typhoid fever became ill enough to go to bed, thus differing from Table II, which shows the dates on which the cases were reported to the health department.

No bacteriologic examination of the city's drinking water was made between the dates July 19 and 29 . On the later date the city's supply pipes were thoroughly flushed; this reduced the possibility of finding traces of the supposed contamination to a minimum. It was estimated by the water department that about 500,000 gallons of sewage or Merrimac River water found its way into the city's water service between the hours of 2 a. $\mathrm{m}$. and 9 a. $\mathrm{m}$. July 19 , before the defective valve was discovered. This amount is equivalent to about one-twelfth the average daily consumption of city water. There is no way of estimating how long before 2 a. $m$. the two systems had been in communication. On July 29 (ten days after the contamination) the State Board of Health made a bacteriologic examination of the water. The following report, which I am permitted to publish through the kindness of the water department, explains the findings of that examination:

\section{OFFICE OF THE STATE BOARD OF HEALTH.} Boston, Aug. 26, 1903.

To the Lowell Water Board, Lowell Mass.

Gentlemen:-In response to your request of July 28 for bacterial examination of the water supply of the city of Lowell, the board caused samples to be collected from various parts of the city on July 29 and again on July 31, and sends you herewith the results.

The average number of bacteria found in different parts of the city on July 29 was 17 , which is nearly the same as the number found at the force-main at the boulevard wells, indicating no added pollution at this time. This number is smaller than the average found in other driven well supplies throughout the state.

On examining these bacteria to learn if Bacillus coli, which is regarded as indicative of pollution by sewage, was present, none was found in any of the samples when the usual amount of one cubic centimeter was examined, but on examining one hundred times this amount this species was indicated in two samples, viz.: one taken from a store in Pawtucketville and one taken from Walker street. In both these cases the whole number of bacteria was unusually small, averaging but ten, indicating a small degree of pollution.

Another series of samples taken on July 31 gave somewhat higher number of bacteria present, but no greater increase than might be expected from the temporary effect of the flushing out of the eity mains on July 29 after the collection of the first series. By this flushing and the subsequent filling the sediment remaining in the mains was probably stirred up, and the bacteria in this sediment and on the sides of the pipes were detached.

The number of bacteria in all of these samples averaged as low as in other driven well'supplies of the state, but the presence of Bacillus coli, even in small numbers, was an un. usual occurrence. With the first four samples of the second series all of the bacteria in 1,000 c.c. were also examined with no indication of Bacillus coli.

(Signed)

Samuel W. Аввотt, Secretary.

The water supply from this source had been regularly examined and had nerer shown the presence of the Bacillus coli.

TYPE OF THE EPIDEMIC.

As a whole, the disease was of a mild character, the death rate being 4.4 per cent. The city bacteriologist, in a personal letter to the writer, says: "The unusual increase in the number of cases of typhoid fever was noticed about August 1. Counting from that date to the end of September, 90 specimens of blood were received here. Of these 58 were positive, 25 were negative, 7 unsatisfactory for various reasons. In some of these the examination was repeated twice or three times before getting a positive result." Cases at the hospitals (about 50) were verified there, consequently do not figure in the above report. From a study of about seventy-five cases of the epidemic, seen at the hospitals and in prirate practice, the following characteristies prevailed: Onset sudden and often accompanied by a chill; temperature high at the start (102 to 104) and remaining high well into the third week; pulse slow and not in proportion to the temperature, being more often under 100 than over; diarrhea present in 55 per cent. of these cases; rose spots present in 80 per cent., and diazo-reaction positive in 90 per cent. of all cases, giving a rositive Widal test; nose bleed absent in 90 per cent. of all the cases; the average duration of the fever was twentyseven days, with a slow convalescence. Among the complications occurring the following were the most marked: Phlebitis in 8 cases, bronchitis in 6 cases, otitis in 4 cases, arthritis in 4 cases, neuritis in 2 cases, acute mania in 1 case, edema of the lungs 1 case, endocarditis 1 case (death). There were 8 cases of intestinal hemorrhage, 1 with a second hemorrhage. None of these died.

There were several cases in which the clinical picture of typhoid fever was not substantiated by a positive Widal test. These cases did not have rose spots nor an enlarged spleen. The complications mentioned above were as frequent in this class of cases as in the genuine typhoid. There were no means at hand to prove whether these belonged to the paratyphoid group, although this clinical diagnosis seemed well established.

I desire to acknowledge my indebtedness to the Massachusetts State Board of Health and to the Lowell water and health departments for their kindness in furnishing me with the results of their respective investigations.

\section{THE UNITED STATES PHARMACOPEIA OF 1900.*}

CARL S. N. HALLBERG, PH.G.

Member of the Committee of Revision. CHICAGO.

The revision of the Pharmacopeia begun by the committee elected at the decennial convention in Washington, in 1900 , is progressing as rapidly as is warranted by the importance and magnitude of the work.

The committee lost its chairman in 1901, Dr. Charles Rice, pharmacist to the Department of Public Charities and Corrections of New York, who had filled that position with especial credit since 1880 , and suffered further loss in the death of a life-long worker, Dr. Edward $P$ Squibb of Brooklyn. The death of the chairman at a critical point of the work caused some delay until the vacancy was filled by Prof. Joseph P. Remington of Philadelphia. Partly due to this fact, but more especially owing to the many important questions, never before confronting a committee of revision, requiring solu-

- Read at the Fifty-fourth Annual Session of the Ameriran Medical Association, in the Section on Materia Medica, Pharmacy and Therapeutics, and approved for publication by the Executive Committee: Drs. S. Solis-Cohen, George F. Butler and $\mathbf{N}$. $\mathbf{S}$ Davis, Jl: 
tion, the work of ievision has been more than usually delayed so that the book will in all probability not appear until in 1904. The official life of the U. S. Pharmacopeia will, therefore, not be synchronous with its decennial designation (1900-1910), which, however, is not of any especial significance.

\section{THE SUBCOMMITTEES.}

As an indication of the scope and character of the work of revision the enumeration of the following subcommittees and the subject allotted to each may be of interest:

1. 'Therapeutics.

2. Posology.

3. Botany and pharmacognosy.

4. General and inorganic chemistry.

5. Organic chemistry; also fixed oils and fats.

6. Proximate assays.

7. Volatile oils and allied substances.

8. Extracts, tinctures, etc.

9. Aromatic waters and spirits.

10. Cerates and allied compounds.

11. Syrups and elixirs.

12. Miscellaneous galenicals.

13. Weights and measures.

14. Scope and statistics.

15. Nomenelature.

LIMITATION OF PURITY.

Among the most important subjects for consideration, and one which heretofore has received but little attention, was the limitation of purity of medicinal chemicals. To the medical mind, the propriety of this question may well appear doubtful. Why should there be any limitation? Only the purest is sufficient for medicinal uses, or for the purposes of the physician. The proposition is, however, not so simple, since there are certain requirements of a practical character which must be taken into consideration. The U. S. Pharmacopeia (1890), now official, requires for a number of largely used chemicals a greater degree of purity than is obtainable by ordinary chemical processes, a standard-as is claimed by reputable manufacturers-to be obtained only by such expensive processes as to necessarily increase the cost of the product, and as to be in some instances almost prohibitive.

It should be clearly understood, however, that these impurities comprise mostly the presence of very small quantities, sometimes 1 per cent. or less, of sulphates and chlorids in bromids, iodids, phosphates and similar salts, the contention on the part of manufacturers being that the removal of such traces of these foreign salts would be exceedingly difficult, and since their presence could have no possible therapeutic significance, their absolute removal would be a useless expenditure.

Some instances were cited in support of the contention that the presence of even slight traces of foreign salts, innocuous of themselves, might under certain conditions produce entirely unexpected results; thus, for example, when potassium bromid is prescribed with barium chlorid in watery solution, there will be a precipitate of the insoluble barium sulphate in the presence of the slightest trace of sulphate in the potassium bromid. Such instances are, however, exceedingly rare and do not impair the position that mere traces of such impurities in these salts should not be excluded by the U. S. Pharmacopeia.

Another reason for not setting the standard too high is that it is impracticable to have two standards official, and since the pure food and drug laws. in some states refer to the U. S. Pharmacopeia as the standard, druggists and dealers would be liable to prosecution for sell- ing chemicals for commercial and technical purposes where so high purity is not required, which deviate from the official standard of purity. Such prosecution, mostly ill advised, has been frequent in Ohio, and has been carried on to such an extent in the United Kingdom as to make such laws exceedingly unpopular, and alienating the support of a large and otherwise law-abiding element.

In quite a different category is the degree of purity as related to freedom from poisonous compounds, frequently contaminating medicinal chemicals. Compounds of poisonous elements, such as arsenic, copper, lead, tin, derived from the crude products in the process of manufacture, can not be too rigidly excluded. That no convenience of manufacturers or additional cost, no matter how great, will have any influence on the standard of purity required by the U. S. Pharmacopeia in these particulars is a foregone conclusion.

\section{ISOLATED PRINCIPLES.}

The question of substitution of isolated principles for natural products has come to the front largely during the present decade. Many of the volatile oils are mixtures of certain principles, such as the oils of eucalyptus, caryophyllus, cinnamon, gaultheria, betula and sassafras. While the pharmacology on these articles is meager, it is assumed that the principal principles represent the therapeutic virtues of the respective oils, and it is contended that, since these vary considerable in the amount of these principles contained, greater accuracy and uniformity would be secured by the substitution of these principles for the natural oils.

Among the principles of this and similar classes likely to be admitted to the U. S. Pharmacopeia are: Anethol, eugenol, guaiacol and guaiacol earbonate and saffrol. Eucalyptol and methyl salicylate are now official.

\section{SYNTHETICS.}

The admission of synthetic products controlled by patent or proprietary rights has also received much attention. The ethical medical position is unequivocally opposed to the recognition of any substance whose composition is secret, or the manufacture of which is in any manner not free; and yet medieal men, even the very highest authorities, prescribe them and exploit them in the journals. While the Pharmacopeia is supposed to have ignored them, such is not the case. The first synthetic medicinal chemical made by a patented proce'ss, salicylic acid, was admitted to the U. S. Pharmacopeia in 1880. In the present U. S. Pharmacopeia (1890) they are official of this class in addition to salol and lanolin, although under a name different from the trade name. On this point the instructions of the decennial convention of 1900 to the committee of revision were as follows:

The committee of revision is authorized to admit into the Pharmacopeia any product of nature of known origin; also any synthetized product of definite composition which is in common use by the medical profession, the identity, purity or strength of which can be determined. No compound or mixture shall be introduced if the composition or mode of manufacture thereof be kept secret, or if it be controlled by unlimited proprietary rights.

The committec, desiring to adhere to the spirit, if not strictly to the letter, of the instructions of the convention, after considerable deliberation decided "to admit those substances for which there is, or may be, a product or process patent which expires during this decade (i. e., 1900-10), carrying with it the expiration of the trademarked name, as distinguished from a symbol or device." 
According to this, none that are patented will be admitted if their trade-mark does not expire with their patent, and none that are trade-marked without being patented. Should legal advice conclude that trademarked names expire with patent, then only such that are patented will be admitted whose patents expire before 1910. Among those proposed for admission under this decision are chloralamid, ethyl carbonate, hexamethylene-tetramin, iodol, methylene blue, phenacetin, piperazin, saccharin, phenyl salicylate (salol, now official), sulphonal, trional, aristol and salophen. The following would be excluded: Creosote carbonate, eucain, heroin, holocain, ichthyol, methyl acetanilid and orthoform.

\section{ALKALOIDAI ASSAYS.}

The U. S. Pharmacopeia of 1890 requires a certain alkaloidal standard for opium and cinchona, and the preparations of opium and nux vomica. This list will be largely extended, and assay processes fixing a standard of alkaloidal strength for the preparations of the following drugs have been proposed: Opium, cinchona and nux vomica, belladonna, hyoscyamus and stramonium, coca, guarana and kola, physostigma, ipecac, hydrastis, colchicum, pilocarpus, conium and jalap.

\section{ANTITOXIN,}

One of the most difficult questions for the committee to solve has been the admission of diphtheritic antitoxin. The principle of the Pharmacopeia heretofore has been that, inasmuch as the pharmacist is charged with the responsibility of maintaining the standard of identity, purity, quality and strength of all articles official, the Pharmacopeia must provide such definitions, descriptions, tests and assay processes as will enable him to determine whether or not the articles recognized by the Pharmacopeia respond to the official requirements. Since no biologic or pharmacologic tests have ever been admitted to any Pharmacopeia, presumably because these were not within the province of pharmaceutic practice, the admission of any article whose purity and potency could not be determined except through biologic methods appeared to be an insurmountable obstacle to the admission of any biologic product, and the convention, therefore, declared: "Physiologic tests for determining strength should not be introduced by the committee."

Owing, however, to the transcendant importance of the question of antitoxin, and inasmuch as the instructions of the convention were not directly mandatory, and especially in deference to the physicians on the committee who voiced the sentiment of the profession, evidently unanimous, as to the desirability, if not necessity, for the admission of antitoxin, and in order that the U. S. Pharmacopeia (1900) may not be charged with indifference to the greatest remedial agent of the decade it is to represent, the committee of revision decided to carefully consider the question. The matter was referred to a subcommittee, consisting of the physician-members of the committee, together with a number of eminent specialists in this field, with the late Dr. Walter Reed as chairman. Owing to the untimely and sad death of Dr. Reed, Dr. Theobald Smith was subsequently chosen to act as chairman, and this committee is now formulating a plan by which the antidiphtheritic scrum will in all probability be admitted to the U. S. Pharmacopcia on the plan somewhat similar to that of the German Pharmıcopeia of 1900 .
POSOLOGY.

The question of dosage has always been a bugbear to pharmacists. Some (without being able to formulate the proposition, what is a dose? In the terse manner of Dr. S. Solis-Cohen, "A dose is enough") have felt that the Pharmacopeia was trenching on dangerous ground in endeavoring to adopt an authoritative list of doses. It was charged, however, that the lack of such close list in the only legal authority on medicines materially lessened its value to the practitioners, and that such should be incorporated. The sentiment of the convention being almost unanimous on this question, the committee was instructed to state the average approximate adult dose, and, where deemed advisable, also for children, after all articles which are used or likely to be used internally. These are to be given in metric quantitjes, as well as in approximate customary weights and measures. It is to be the distinct understanding that these doses are not to be regarded as obligatory or as not to be exceeded by the physician whenever in his judgment desirable, and a declaration to that effect is to be prominently made in the book. Its purpose, then, is simply to serve as an authoritative reference guide to pharmacists and physicians.

\section{NOMENCLATURE.}

While the aim of the Pharmacopeia is to adhere to a scientific nomenclature, it can not invariably do so. To change old familiar titles of some chemicals so as to conform to the modern chemical nomenclature would create confusion, be inconvenient in prescribing and dispensing, and impair the usefulness of the alphabetical arrangement. Carbolic acid, for example, would appear as "phenol," and arsenous acid as "arsenic trioxid," if the chemical nomenclature be strictly observed. Since the scientific names are invariably appended as synonyms for such titles, as well as for such articles as may be admitted under trade names, there can be no objection to such deviation from the scientific nomenclature in the official titles as may be determined for the greater safety and convenience of physicians and pharmacists. Sometimes the title appears in contradiction to the chemical name, without apparent justification, as in "chloral" of the U. S. Pharmacopeia of 1890, which sliould have been "chloralis hydras"; chloral being a liquid, the hydrate of which is the well-known crystalline solid. The best of reasons, however, prompted this violation of chemical usage, namely, the belief that the use of the single word in prescribing would avoid the inevitable abbreviation of "chlor. hyd.," and thus prevent confusion with "chlorid hydrarg.," and consequent errors and complications.

\section{DISCUSSION.}

Dr. W. J. Robrnson, New York-I consider the United States Pharmacopeia the best in the world. I am familiar with all of them, and as far as definiteness, succinetness and tests for purity are concerned it ranks above all. Still it is not pppular with the physician. You will seldom find a physician who studies the pharmacopeia and rarely one who owns the book. It has always interested me to know why the physician never refers to the pharmacopeia. Among the many reasons $I$ will mention one-it is the principal onethe pharmacopeia does not contain a very large number of substances which the physician prescribes daily. It contains about 200 various drugs like phytolacca, chelidonium, illi. ciun, inula, mezereum, pareira, juglans, etc., and such substances which the progressive physician of to-day never prescribes, while many of those which are in daily use are 
nut to be found in it. We ean not blame the pharmacopeia for not admitting these substances. Many of them are proprietary remedies with a perpetual copyright, but still it is wrong to exclude them altogether. The solution of the question would probably be to have a pharmacopeia of the same character as the present one which should contain all the standard drugs, but it should have a supplement in which might be given the chief characters of that large class of drugs which are frequently used and of which we know the exact chemical constitution. That would not be giving them the full sanction of the pharmacopeia, but at the same time it would be serviceable to the physician. Concerning the dosage, I think that would be a valuable addition to the pharmacopeia and render it more popular. Of course, there should be no ironclad rule about the dose, as the mention of a definite dose might lead to confusion, but if the average dosage were included it would render the book more useful to both physician and pharmacist.

Dr. B. Prnosin, Chicago-The pharmacopeia should be in the office of every physician, for there is no better souree from which to derive information in regard to the peculiarities of certain drugs. Concerning the bringing into the pharuacopeia of these preparations the patents of which have passed limitation, it should make no difference to the physician whether or not the patent letter has expired. I would prefer a remedy the patent of which is running to one the patent of which has expired-provided the composition and the physiologic action is known to me-for the reason that so long as it is protected and, in the hands of only one manufacturer we know it is pure. When the patent is taken off and other parties take up the manufacture then there is adulteration. I think the doses should be incorporated in the pharmacopeia, as this would give the druggist and physician an equal opportunity to check each other in case of mistakes (on either part). I believe it would be well if the names of some of the drugs could be changed from time to time. Here in America, although it is our own fault, it seems to be a part of our business to tell the patient what he gets. The only benefit I can see from the knowledge of the patient about the drug he gets is to caution the next physician in case of idiosynerasy to a certain drug.

DR: W. B. HuL, Milwaukee, Wis.-The metric system and the dosage are two bugbears of the pharmacopeia of 1900 . It is a simple thing to put down the figures, but to get the people to use them is quite a different matter. I believe the dosage is the key to the situation, but that means a real revision of the pharmacopeia, not a so-called revision. If we add a dosage system to the pharmacopeia, a system in which the strength of the preparations is given, within certain limits we make the use of the metric system possible; in other words, we should make it easier to nane the dose in the metric system than in the English system. There would then be no question about its adoption. If we look over the various preparations we will find that tinctures vary all the way from 5 to 35 per cent., some for a very good reason, others without any reason. Under the metric system the tinctures could be classified in two or three classes, the stronger ones with a uniform dose of $\mathbf{l}$ c.e., the next elass with average dose of 5 c.c., and the third class in larger quantities, such as the weaker tinctures. In this way we inight so simplify the dosage that one could remember more easily in the metric system than in the English system. The greatest difficulty in training the mewory so as to use the metric system is in the very small denominations. The trouble is in the unit, and it is difficult for the student to comprehend it. If the pharmacopeia were arranged in a double manner, on one side the tinctures and triturates, each with a uniform dose, and on the other side the fluid extracts and extracts with a uniform strength, I believe the metric system would be adopted within five years.

Dr. O. T. Osborne, New Haven, Conn.--I believe the trouble lies in our hospitals. At the Yale Medical School I have taught the metric system for nearly twenty years, and will venture to say that not 25 per cent. of our graduates write prescriptions in the metric system to-day. We begin to teach materia medica in the second year, advanced pharmacology in the third year, and applied therapeutics in the fourth year. At the end of the second year the student is better versed in the metric system than he is at the end of the third year, and at the end of the third year he writes better prescriptions than he does at the end of the fourth year. This is because he is constantly coming in contact in journals, textbooks and clinics with preseriptions written in the old system When the student gets into the hospital he sees no more of the metric system, and when he leaves he has almost forgotten that there is such a system. Hence I believe that until the hospitals abolish the old system and take up the new, the medical colleges can not advance the use of the decimal system. As to teaching the doses of preparations, as an example, I classify the tinctures into poisonous and non-poisonous and put as many as possible together under one dose. In this way the student soon learns that a poisonous tincture has a dose of a few drops, and a non-poisonous a dose of a teaspoonful.

Dr. H. A. Moovr, Mobile, Ala.-Dr. Osborne has voiced my experience. I have been teaching materia medica for about ten years. In the first year my students are required to copy prescriptions from the blackboard in the metric system and it is discussed-and I mean discussed-the students are in vited to participate in the discussion and compare the metric system with the old system. In the study of therapeutics the students write the prescription in the old method first and then translate it into the metric system in order to be masters of both systems, for this is necessary if they are to practice in rural districts. The result is that they gravitate to the old system, and nothing seems to stop them. I believe it was Lincoln who said that "you can not fool all of the people all of the time." So I think there must be some solid foundation for the preference for the old system or it would have been dropped long ago. It is a fact that it is the most popular system all over the United States to-day. Dr. Robinson said the pharmacopeia contained a lot of drugs that had become obsolete and were never used by progressive phy sicians, and among other substances he mentioned phytolacca Now, phytolacea is not obsolete all over the country by any means. This illustrates how utterly impossible it will be to satisfy all parties by any decision as to which drugs shall be placed in the pharmacopeia and which shall be omitted, or go into the appendix. You will be sure to offend the sense of propriety of some. Another statement referred to was the physiologic test of drugs. The committee decided that they could not use that test of drugs for the pharmacopeia. It seemed to me that this referred principally to the animal serums. Now, there are other drugs whose strength we can ascertain in no other way, such as ergot, digitalis, etc. Is the physiologic test used to standardize medicines such as these?

Dr. F. R. Weber, Milwaukee, Wis.--We have in our school those who prefer the old system and those who prefer the metric. The effect of this is to accustom the students to one as much as to the other, and it is easy for them to prescribe in either system. It is only laziness that causes them to ignore the metric system. When the metric system was introduced in Germany, within a year all the old books and the old systems were changed. If our books would change and only contain the metric system how quickly would the nation throw off the old system and take up the new. The trouble with the United States is that we still prefer to read English articles, and in England it is practically impossible to intro duce the metric system.

Dr. C. S. Chamberin, Cincinnati-There must be some reason for the hold which the old system has on us. I studied both systems when at college and for three years taught chem. istry, using the metric system entirely. In my practice I tried to use the metric system, but I never got beyond the point where I did not have to translate from the oud into the new. In regard to phytolacea, Dr. J. B. Shoemaker has an article in the October, 1901, Medical Bulletin which covers 
at least four pages, in which he declares that it is one of the best alteratives and the best of all remedies in mastitis.

Pror. C. S. N. HALLBERG-With reference to the scope of the pharmacopeia it has been very diflicult to get anything like statistics in the United States. We have compiled the different kinds of articles which enter into hundreds of thousands of prescriptions in the different sections of the United States and we never before realized what a vast country this is. The medicines which may be considered obsolete in one section are used in great quantity in another section. You must remember that we have here in the United States a medical and a pharmaceutical population which is cosmopolitan. The United States Pharmacopeia may well be considered a combination of all the pharmacopeias of Europe revised and condensed. The committee does its best in getting information as to what these articles are and which should be admitted. As to the supplement, which should include a number of articles, as suggested by Dr. Robinson, I believe that is a questionable expedient. The pharmacopeia has a legal standing, not by act of congress, but by laws in the states whereever there is legislation affecting pharmacy or pure food and drug laws; in such states it is recognized as the standard. Of course, if these articles were simply enumerated therein it might serve a purpose, but that is doubtful. The American Pharmaceutical Association issues a National Formulary and it might be advisable to enumerate in that such articles as Dr. Robinson suggests. That the strength of galenic preparations sliouid be based on the posology instead of on the drug strength is a new proposition and one not recognized in any pharmacopeia. The pharmacopeia is first of all the hand-book of the pharmacist; it is his manual from which he makes his preparations, as far as the galenic preparations are concerned, and because of the use of the metric system it is desired to maintain the percentage proportions. Any change, therefore, which would involve too much deviation would be embarrassing to the pharmacist. To fix even the general average doses of these preparations would make them of a strength without any determined relation to the drug. Dr. Wood, for instance, administers tincture of digitalis in teaspoonful doses, while other's give one-fourth that amount. Now, what should be the drug-strength of tincture of digitalis? To obviate this confusion last year at Brussels there was a conference "for the unification of the strength of potent remedies." Dr. H. C. Wood, Philadelphia, attended this international conference, at which were representatives from every country in Europe. It was decided that tinctures should be in two classes, the potent drugs of a 10 per cent. and those less potent of 20 per cent. strength. That will be a great pharmaceutic convenience, though it does not conform to Dr. Hill's suggestion except to the extent that there is a distinction between potent drugs and those that are less potent. But here arises a great difficulty; the tinctures of the most potent drugs are of the greatest drug strength; tincture of aconite is 35 per cent., tineture of veratrum viride is 40 per cent. in strength, while tinctures of drugs which can not approach these in potency are only 10 , or $\overline{0}$ per cent. The committee has, however, decided to follow this principle, and is going to change the strengths of the tinctures of aconite and veratrum viride to 10 per cent. There is a tendency toward the unification of potent remedies, and this conference fixed the strength of all arsenical solutions at 1 per cent., which is uniform in all the pharmacopeias. The question of patents raised by Dr. Pirosh is - scarcely within the limits of the paper. A patent is limited to seventeen years. There is no objection to a patent, but what we call "patent remerlies" are of secret composition and some get the name of being patented from the fact that the name or label has been copyrighted and the profession is not furnished the formula. The only way to learn the metric system is to work with it. Pharmacy students have to work with the metric system in all branches. Annually, during the course, a vote is taken among the students as to their preference, and only once in ten years one man said he preferred the old system after working with the metric system for three months. The great advantage of the metric system is shown in recent works on pharmacy and therapeutics. In the older works an ointment, for example, has to be prescribed "a dram to the ounce," or "30 grs. to the ounce." Compare that method of expression to the clear, concise statement that an ointment is 1 per cent., or 2 per cent., or 10 per cent. strength. Applied to solutions and preparations for external use the metric system goes hand in hand with percentage strengths, and is the only scientific method of expression.

\section{HOW FAR SHOULD THE SPECTATIST IN RHINOLOGY AND OTOLOGY PRESUME TO TREAT THE SYSTEMIC CONDI- TION OF HIS PATIENTS ?* CAROLUS M. COBB, M.D. BOSTON.}

In many of the papers dealing with the treatment of catarrhal conditions of the nose, throat and ears, we find such suggestions as the following: "The general bealth should be carefully looked after," "any deviation from the standard of health should be corrected," some putting the case stronger and claiming that no success can be hoped for unless the general health of the patient is made perfect, or at least made better. If this is the case, our first inquiry should be in regard to the qualification of the specialist. Is he able and prepared to make a diagnosis of all the obscure conditions of the general system which the general practitioner has overlooked? If he is able to do so will he do it in the short time which he generally devotes to the consideration of a case? Assuming that he is able and willing to do this, should he treat the case or should he refer the patient to his family physician, explaining to him that the local disease depends on such and such a general condition? These are serious questions, and it is fully time that we stated definitely just what we mean. In discussing these questions I shall simply state my views with the purpose of arriving at some definite conclusion as to the course to pursue.

It is a well-known fact in all branches of human knowledge that the more distinctly a man is a specialist, the less his opinion is worth about general questions, and often about subjects intimately connected with his own specialty. If this is so in the exact sciences, how much more is it likcly to be true in medicine? There are several reasons why, in my opinion, the specialist is not as well qualified to make a diagnosis and, therefore, to treat the general condition. The first of these is the fact that he sees most diseases through the medium of his own specialty; secondly, he often does not have the requisite training, and if he has it he soon gets out of touch with the subject of general medicine; thirdly, he does not keep touch with the literature of general medicine; fourthly, he does not have at his command the necessary instruments of precision; fifthly, the patient comes to him for another purpose and does not volunteer information with which his family physician is perfectly familiar, and, lastly, he does not take the necessary time to inrestigate the functions of the different organs and to obtain a complete history of the general health. It is only by such a painstaking investigation that an accurate diagnosis can be made.

On the other hand, the specialist often sees the local manifestations of disease conditions which may have been overlooked and which perhaps the family physi-

* Read at the Fifty-fourth Annual Session of the American Med ical Association, in the Section on Laryngology and Otology, and approved for publication by the Executive Committee: Drs. George L. Richards, Joachim and G. V. Woollen. 